\title{
Étienne Jodelle, Didon se sacrifiant. Tragédie
}

\section{Michele Mastroianni}

\section{(2) OpenEdition}

\section{Journals}

\section{Edizione digitale}

URL: https://journals.openedition.org/studifrancesi/39107

DOI: 10.4000/studifrancesi.39107

ISSN: 2421-5856

\section{Editore}

Rosenberg \& Sellier

\section{Edizione cartacea}

Data di pubblicazione: 1 décembre 2004

Paginazione: 348

ISSN: 0039-2944

\section{Notizia bibliografica digitale}

Michele Mastroianni, «Étienne Jodelle, Didon se sacrifiant. Tragédie», Studi Francesi [Online], 143 (XLVIII | II) | 2004, online dal 30 novembre 2015, consultato il 19 mai 2021. URL: http://

journals.openedition.org/studifrancesi/39107 ; DOI: https://doi.org/10.4000/studifrancesi.39107

Questo documento è stato generato automaticamente il 19 mai 2021.



Studi Francesi è distribuita con Licenza Creative Commons Attribuzione - Non commerciale - Non opere derivate 4.0 Internazionale. 
Étienne Jodelle, Didon se sacrifiant. Tragédie

Michele Mastroianni 


\section{NOTIZIA}

ÉTIENNE JODELLE, Didon se sacrifiant. Tragédie, édition critique établie, présentée et annotée par JEAN-CLAUDE TERNAUX (Théâtre complet, publié sous la direction de Christine de Buzon et Jean-Claude Ternaux: tome III), Paris, Champion, 2002, pp. 159.

1 Nel quadro del Théâtre complet di Étienne Jodelle, che sarà pubblicato sotto la direzione di Christine de Buzon e Jean-Claude Ternaux, compare, come prima uscita, l'edizione critica della Didon se sacrifiant, a cura di J.-Cl. Ternaux. Come per le precedenti edizioni di E. Balmas (É. JoDELLE, Cuvres complètes, Paris, Gallimard, 1965-1968, t. II, pp. 149-216) e di A. Miotti (Théâtre Français de la Renaissance, dir. par E. Balmas et M. Dassonville, première série, vol. 5, Firenze-Paris, Olschki-P.U.F., 1993, pp. 341-430), viene riprodotto, con l'inserimento delle rarissime correzioni (due) dell'edizione del 1583, il testo edito nel 1574, un anno dopo la morte di Jodelle, da Charles de La Mothe in Les Cuvres et Meslanges Poëtiques d'Estienne Jodelle. A differenza delle precedenti edizioni viene rispettata totalmente l'ortografia dell'edizione cinquecentesca. Nell'introduzione (pp. 7-24) J.-Cl. Ternaux inquadra la tragedia nella storia della fortuna sia della tematica teatrale di Didone sia del personaggio nella letteratura dell'Umanesimo, a partire dal $D e$ claris mulieribus boccacciano, inserendola anche nel contesto degli influssi della tragedia italiana cinquecentesca. In particolare, Ternaux sottolinea il carattere più epico che tragico del testo di Jodelle, nei suoi rapporti con l'Eneide. In questa direzione sono utili le note che accompagnano il testo, istituendo un continuo raffronto con il poema virgiliano. L'edizione è completata da un accurato glossario con la localizzazione delle occorrenze. Utili gli indici (dei nomi, delle nozioni e dei temi) e, in particolare, una tavola dei paragoni e delle metafore. 